\title{
Primary vitrectomy for pseudophakic retinal detachment
}

\author{
Karl Ulrich Bartz-Schmidt, Bernd Kirchhof, Klaus Heimann
}

\begin{abstract}
Aim/Background-Viewing the peripheral retina is the major problem in the repair of pseudophakic retinal detachments. Conventional buckling procedures in pseudophakic eyes are complicated by persistent retinal (re-) detachment and proliferative vitreoretinopathy (PVR) more often than in phakic eyes.

Methods-Primary vitrectomy was performed in 33 consecutive cases for pseudophakic retinal detachment with the help of liquid perfluorocarbons and a wide angle viewing system, following a standardised procedure. All eyes have passed the 12 month follow up examination.

Results-The primary reattachment rate was $94 \%$. PVR was observed in one case (3\%). Seventy nine per cent (26 eyes) regained vision of $20 / 50$ or better, with a median visual acuity of $20 / 30$. The most frequent complication was transient glaucoma during the early postoperative period in $48 \%$ (16 eyes) requiring carboanhydrase inhibitors.

Conclusion-The main advantage of primary vitrectomy over conventional buckling seems to be the better intraoperative sight to the most peripheral retinal holes, controlled removal of vitreous traction, and focused endolaser coagulation. This may explain the low rate of PVR after primary vitrectomy. Also, visual results tended to be better compared with conventional surgical techniques possibly because of removed vitreous opacities, and because of a superior retinal reattachment rate as well as the reduced rate of PVR.

(Br f Ophthalmol 1996; 80: 346-349)
\end{abstract}

Viewing the peripheral retina is the major problem in the repair of pseudophakic retinal detachments. The difficulty evolves from refraction at the rim of the implant, cortical remnants, and/or opacifications of the posterior or anterior capsule, or less frequently simply from a small pupil in iris suspended lenses.

Conventional buckling procedures in pseudophakic eyes are complicated by persistent retinal (re-) detachment more often than in phakic eyes: phakic $9 \%$ to $25 \%$; pseudophakic $10 \%$ to $35 \%$, and by proliferative vitreoretinopathy (PVR): phakic 5\% to $10 \%$; pseudophakic $5 \%$ to $20 \%$. $^{1-6}$ In our series such complications were strongly associated with failure to localise the retinal hole(s) and excessive retinopexy. ${ }^{7}$ With the unsatisfactory prognosis of 'blind buckling' in mind we initiated vitrectomy for pseudophakic retinal detachments as a primary procedure. The reasons for vitrectomy were optimal sight into the eye and less traumatic surgery by modern vitrectomy techniques and equipment.

It is thereby possible to remove opacities in the anterior segment of the eye via pars plana. Localisation of the retinal holes and vitreoretinal traction becomes easier because of the indirect 130 degree wide angle contact lens, indentation, and intraocular fibre illumination. With the help of liquid perfluorocarbons and wide angle viewing systems vitrectomy has become safer. The aim of primary vitrectomy was to reduce the rate of retinal redetachment as a consequence of proliferative vitreoretinopathy, and thereby to improve the functional outcome.

\section{Patients and methods}

Thirty three consecutive patients ( 33 eyes), 15 women and $18 \mathrm{men}$, were recruited in the period between June 1993 to the end of March 1994 in the Department of Ophthalmology at the University of Cologne in Germany. Ages ranged from 29 to 88 years (average 64 years).

All patients suffered acute retinal detachment after cataract surgery with implantation of an intraocular lens (Table 1). All patients with signs of PVR higher than grade $B,{ }^{8}$ proliferative diabetic retinopathy, uncontrolled glaucoma or uveitis, vitreous bleeding, endophthalmitis, giant tear, or history of severe eye trauma were excluded.

All patients recruited for primary vitrectomy gave informed consent to be treated by vitrectomy (described to them as a new investigative approach) as opposed to conventional buckling surgery.

Preoperative evaluation included measurement of visual acuity and intraocular pressure (IOP), anterior and posterior slit-lamp biomicroscopy, indirect ophthalmoscopy, and ultrasonography when required. All patients were examined daily until discharge and thereafter 6 weeks, 6 month, and 1 year after surgery.

Table 1 Characteristics of 33 pseudophakic eyes with retinal detachment

\begin{tabular}{lc}
\hline Characteristic & No of eyes \\
\hline Intraocular lens & \\
Posterior & 31 \\
Anterior & 2 \\
Vitreous loss & 4 \\
YAG capsulotomy & 11 \\
Myopia ( >-6 D) & 13 \\
Macula off & 17 \\
Detection of hole & 9 \\
No hole preoperatively & 7 \\
No hole according to Lincoff preoperatively & 2 \\
No hole intraoperatively & 6 \\
Additional hole intraoperatively & \\
\hline
\end{tabular}

\footnotetext{
Correspondence to: Karl U Bartz-Schmidt, MD, Universitäts-Augenklinik D-50924 Köln, Germany.

Accepted for publication 21 December 1995

Vitreoretinal Surgery, Germany

K U Bartz-Schmidt

B Kirchhof
} 
Table 2 Complications after primary vitrectomy

\begin{tabular}{|c|c|c|c|c|c|c|c|}
\hline $\begin{array}{l}\text { Patient } \\
\text { no }\end{array}$ & $\begin{array}{l}\text { PVR } \\
\text { redetachment }\end{array}$ & $\begin{array}{l}\text { Rhegmatogenous } \\
\text { redetachment }\end{array}$ & $\begin{array}{l}\text { Macular } \\
\text { pucker }\end{array}$ & $\begin{array}{l}\text { IOP rise } \\
\geqslant 30 \mathrm{~mm} \mathrm{Hg}\end{array}$ & $\begin{array}{l}\text { Anterior } \\
\text { synechia }\end{array}$ & $\begin{array}{l}\text { Iris } \\
\text { capture }\end{array}$ & $\begin{array}{l}\text { PFCL } \\
\text { remnants }\end{array}$ \\
\hline 1 & - & - & - & $+++^{\star}$ & - & - & + \\
\hline 2 & - & - & - & $++^{\star}$ & - & - & - \\
\hline 3 & - & - & - & + & - & - & - \\
\hline 4 & - & - & - & + & - & - & - \\
\hline 5 & - & - & - & + & + & - & - \\
\hline 6 & - & - & - & + & - & - & - \\
\hline 7 & - & - & - & + & - & - & - \\
\hline 8 & - & - & - & + & - & - & - \\
\hline 9 & - & - & - & + & - & - & - \\
\hline 10 & - & - & - & + & - & - & - \\
\hline 11 & - & - & - & + & - & + & - \\
\hline 12 & - & - & - & + & - & - & - \\
\hline 13 & - & - & - & + & - & - & - \\
\hline 14 & - & - & - & + & - & + & - \\
\hline 15 & - & - & - & + & - & - & - \\
\hline 16 & - & + & - & - & - & - & - \\
\hline 17 & + & - & + & - & - & - & - \\
\hline 18 & - & - & - & - & + & - & - \\
\hline 19 & - & - & - & - & - & + & + \\
\hline 20 & - & - & - & $+++^{\star}$ & - & - & - \\
\hline Total & 1 & 1 & 1 & 16 & 2 & 3 & 2 \\
\hline
\end{tabular}

$\star_{+}++=\mathrm{IOP} \geqslant 50 \mathrm{~mm} \mathrm{Hg},++=\mathrm{IOP} \geqslant 40 \mathrm{~mm} \mathrm{Hg}$. PVR=proliferative vitreoretinopathy; $\mathrm{PFCL}=$ perfluorocarbon liquids

Preoperative topical cycloplegics were used and a combination of antibiotic/steroid preparations was continued as needed for several weeks after surgery.

We performed vitrectomy under general anaesthesia in all patients using a three port technique under the operating microscope and with the use of a wide angle viewing system (Oculus 130, Oculus Wetzler, Germany) in a standardised procedure. Firstly, an encircling band was placed at $13 \mathrm{~mm}$ distance from the limbus (pre-equatorial) to support the vitreous base. Secondly, we removed the posterior vitreous followed by injection of perfluorodecalin to stabilise the central retina during examination of the vitreous base. After tightening the encircling band for easier removal of the vitreous base we additionally removed the flap of the tear to abolish vitreal traction. Peripheral endodrainage of subretinal fluid through the hole was performed using fluid air exchange and completed by removal of the perfluorodecalin. Then we applied endolaser treatment around the hole and circularly on the encir-

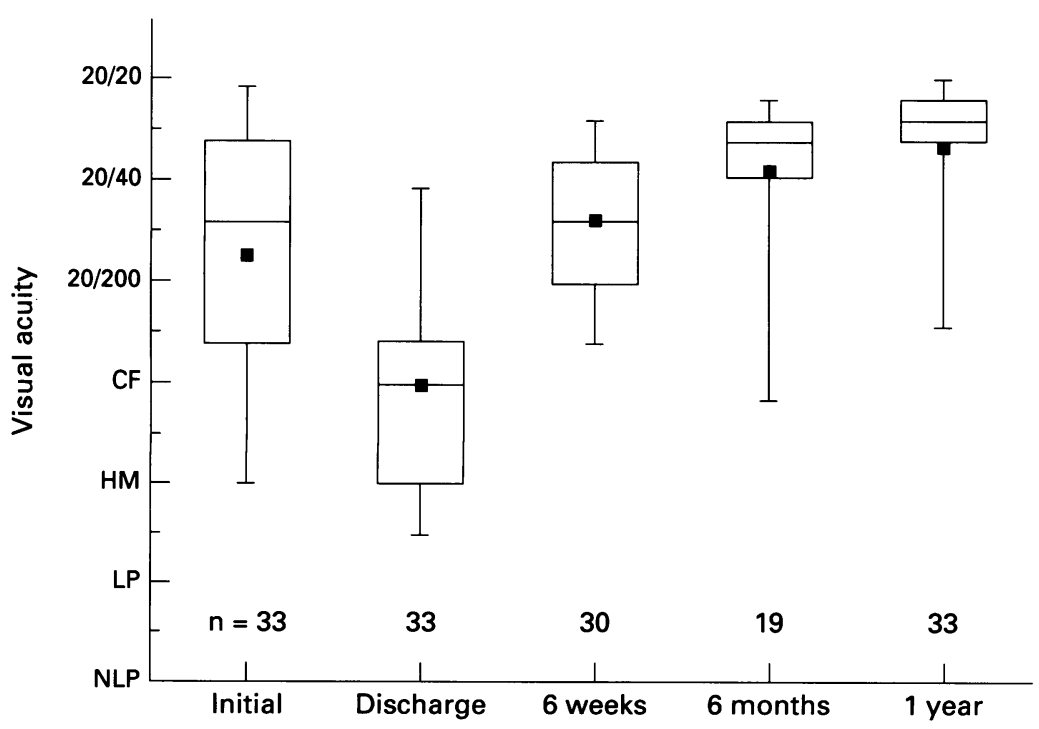

Figure 1 Visual acuity at the initial examination, at discharge, 6 weeks, 6 months, and 1 year after primary vitrectomy. $n=$ number of patients, $C F=$ counting fingers, $H M=$ hand movements, $L P=$ light perception, NLP=no light perception, $\square=$ mean visual acuity (calculated after transforming into logMAR units). cling buckle. The operation ended by air gas exchange $\left(\mathrm{C}_{3} \mathrm{~F}_{8}\right)$ and adjustment of the tightness of the encircling band and the intraocular pressure to $17 \mathrm{~mm} \mathrm{Hg}$.

\section{Results}

\section{REATTACHMENT}

The retina was reattached in 31 cases with one operation (94\%) and in all eyes after a second procedure. One patient developed a rhegmatogenous redetachment 27 days after primary vitrectomy, probably due to incomplete vitrectomy. The retina was detached as the result of a new break at the 6 o'clock position central to the encircling buckle. We reattached the retina using retinocryopexy around the break and placement of an additional circumferential buckle central to the encircling band. In a second patient redetachment was associated with the development of PVR with reopening of the previous retinal break, 32 days after primary vitrectomy. In a second procedure we removed these epiretinal membranes. The retina reattached after injection of perfluorocarbon liquids, endolaser photocoagulation and fluid gas exchange (Table 2).

\section{VISUAL ACUITY}

The median of best corrected visual acuity before surgery was 20/100. Owing to the gas endotamponade median visual acuity decreased to $20 / 800$ at the time of discharge. At the 6 week interval, the gas endotamponade was partially resolved in almost all of the cases. Median visual acuity increased to 20/100. After 6 months, median visual acuity was 20/40, but 14 patients missed the control examination at this interval. However, all patients passed the 1 year follow up examination. Median visual acuity 1 year after primary vitrectomy was 20/30 (Fig 1). Macula on detachments obtained vision of $20 / 50$ or better in $81 \%$ (13 eyes); for macula off detachments visual recovery to the $20 / 50$ level or better could be achieved in $76 \%$ (13 eyes).

\section{PREOPERATIVE BREAK DETECTION}

In nine eyes no breaks were detected preoperatively. In a further seven eyes preoperative localisation of the break did not comply with the rules of Lincoff, ${ }^{9}$ but corresponding breaks were found intraoperatively. In all but two eyes vitrectomy and the use of perfluorocarbon liquid (to express the Schlieren phenomenon) revealed the causative retinal break. In a further six eyes an additional break, not seen in the preoperative examination, could be identified.

\section{COMPLICATIONS}

In one eye, macular pucker occurred 56 days after revisional surgery of PVR redetachment. After removing the epiretinal membrane in a third procedure the retina remained stable. Revision of the anterior segment was necessary 
in two eyes because of anterior synechia, in the presence of chamber angle supported anterior chamber lenses. A further three eyes were complicated by iris capture. These three eyes had a sulcus fixed posterior chamber lens and a central opening of the posterior lens capsule. Two eyes depicted perfluorodecalin remnants in the chamber angle, which we removed by paracentesis.

Sixteen eyes showed elevated IOP of more than $29 \mathrm{~mm} \mathrm{Hg}$ during the first 24 hours after surgery; two of these eyes had an IOP above 50 $\mathrm{mm} \mathrm{Hg}$ and one eye above $40 \mathrm{~mm} \mathrm{Hg}$. Despite intravenous application of acetazolamide one eye developed a central artery occlusion.

None of our cases developed a choroidal detachment, explant extrusion, or strabismus.

\section{Discussion}

Our results indicate that pars plana vitrectomy offers a number of advantages to the retinal surgeon in the management of pseudophakic retinal detachments. It eliminates media opacities in the anterior and posterior segment. It allows for easy localisation of retinal holes and removal of vitreoretinal traction, and it facilitates more precise treatment of retinal breaks by endolaser.

The $4 \%$ incidence of postoperative PVR in our series is lower compared with other reported series of rhegmatogenous retinal detachment treated with primary vitrectomy. ${ }^{51011}$ The reason for the low rate of PVR might be the ability to view up to the most peripheral fundus during surgery using indirect wide angle optics, which was not used by others. Together with the use of liquid perfluorocarbons to immobilise the peripheral retina, the vitreous could be completely removed under controlled conditions. Furthermore, the risk of iatrogenic retinal injuries was minimised by the use of heavy liquids in combination with the wide angle viewing system.

The disadvantage of the pseudophakic situation in retinal detachment becomes an advantage for vitrectomy surgery. In the presence of a lacing encircling band, intraocular manipulation, especially during removal of anterior vitreous, is easier than in phakic eyes and cannot result in lens opacification during or after surgery. However, vitrectomy cannot completely remove all vitreous traction. For that reason, we left the adjusted encircling band at the end of the procedure and additionally performed a 360 degree laser treatment on the buckle and around the retinal breaks.

In six eyes retinal breaks were found intraoperatively which had not been recognised preoperatively. Despite the excellent view up to the peripheral fundus we were unable to detect the causative retinal hole in two eyes. Also, injection of perfluorocarbon liquid ${ }^{\star}$ did not help to localise breaks in these eyes. Therefore, we created a small retinotomy over the encircling band at the 12 o'clock position, in order to drain the subretinal fluid.

*Inducing the 'Schlieren phenomenon' from proteinaceous subretinal fluid entering the vitreous proteinaceous subretinal fluid entering the
cavity through the peripheral retinal hole. 512
Visual results tend to be better after 6 months and 1 year compared with conventional surgical techniques. 24713 This reflects the better primary retinal reattachment rate and the apparent reduced incidence of PVR, and also the removal of vitreous opacifications during the procedure. The main disadvantage of this therapy is delayed visual restitution (up to 6-8 weeks) from the slow resorption of the gas filling. Furthermore, postoperative positioning is demanding for the elderly patient. Also, air travel must be strictly avoided until complete resolution of the gas bubble. ${ }^{14}$

As a result of the gas expansion, the main problem in our series was IOP rising above 29 $\mathrm{mm} \mathrm{Hg}$ during the first 24 hours after surgery. Despite regular monitoring of IOP during the first night after surgery and systemic treatment using acetazolamide, one patient in our series developed a central retinal artery occlusion. Elevated IOP is a frequent complication following fluid gas exchange $\left(\mathrm{SF}_{6}, \mathrm{C}_{3} \mathrm{~F}_{8}\right)$. It occurs in about $26 \%$ to $59 \%$ of cases. ${ }^{15-17}$ Early postoperative glaucoma is caused by expansion of the gas bubble from nitric oxide and oxygen uptake. Also, an angle block mechanism may result from anterior choroidal swelling due to the encircling band. In our series, however, we did not observe a shallow anterior chamber nor a chamber angle block.

We conclude from these data that primary vitrectomy and scleral buckling for pseudophakic retinal detachment is superior to buckling alone. This holds for functional improvement and rate of PVR. A prospective randomised multicentric study on this subject has begun at the request of the German Retinological Society.

Presented in part at the Xth Congress of the European Society of Ophthalmology, Milan, Italy, 25-29 June 1995.

1 Chignell AH, Fison LG, Davies EW, Hartley RE, Gundry MF. Failure in retinal detachment surgery. Mod Probl Ophthalmol 1974; 12: 20-8.

2 Ho PC, Tolentino FI. Pseudophakic retinal detachment. Surgical success rate with various types of IOLs. Ophthalmology 1984; 91: 847-52.

3 Ruprecht KW, Medenblik-Frysch S, Handel A. Results of pseudophakic retinal detachment surgery. Klin Monatsbl Augenheilkd 1991; 198: 518-21.

4 Wilkinson CP. Pseudophakic retinal detachments. Retina 1985; 5: 1-4.

5 Wong D, Billington BM, Chignell AH. Pars plana vitrectomy for retinal detachment with unseen retinal holes. Graefes Arch Clin Exp Ophthalmol 1987; 225: 269-71.

6 Vatne HO, Syrdalen P. Retinal detachment after intraocular lens implantation. Acta Ophthalmol (Copenh) 1986; 64: 544-6.

7 Bartz-Schmidt KU, Kirchhof B, Heimann K. Risk factors for PVR-redetachment following conventional surgery for pseudophakic retinal detachment. Klin Monatsbl Augenheilkd 1996; 208: 82-6.

8 Machemer R, Aaberg TM, Freeman HM, Irvine AR, Lean JS, Michels RM. An updated classification of retinal detachment with proliferative vitreoretinopathy. $A m \mathcal{F}$ Ophthalmol 1991; 112: 159-65.

9 Lincoff H, Gieser R. Finding the retinal hole. Arch Ophthalmol 1971; 85: 565-9.

10 Gartry DS, Chignell AH, Franks WA, Wong D. Pars plana vitrectomy for the treatment of rhegmatogenous retina detachment uncomplicated by advanced prolifera tive vitreoretinopathy. Br 7 Ophthalmol 1993; 77 199-203.

11 Hakin KN, Lavin MJ, Leaver PK. Primary vitrectomy for rhegmatogenous retinal detachment. Graefes Arch Clin Exp Ophthalmol 1993; 231: 344-6.

12 Lincoff H, Kreissig I. Finding the retinal hole in the pseudophakic eye with detachment. Am $\mathcal{f}$ Ophthalmol 1994; 117: 442-6.

13 Smith PW, Stark WJ, Maumenee AE, Enger CL Michels RG, Glaser BM, et al. Retinal detachment after 
extracapsular cataract extraction with posterior chamber intraocular lens. Ophthalmology 1987; 94: 495-504.

14 Dieckert JP, O'Connor PS, Schacklett DE, Tredici TJ, Lambert HM, Fanton JW, et al. Air travel and intraocular gas. Ophthalmology 1986; 93: 642-5.

15 Abrams GW, Edelhauser HF, Aaberg TM, Hamilton LH. Dynamics of intravitreal sulfur hexafluoride gas. Invest Ophthalmol 1974; 13: 863-8.
16 Lincoff H, Coleman DJ, Kreissig I, Rirchard G, Chang S, Wilcox L. The perfluorocarbon gases in the treatment of retinal detachment. Ophthalmology 1983; 90: 546-51.

17 Sabates WI, Abrams GW, Swanson DE Norton EDW The use of intraocular gases: the results of sulfur hexafluoride gas in retinal detachment surgery. Ophthalmology 1981; 88: 447-54. 